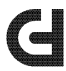 \\ COUNTERFUTURES \\ Left thought \& practice Aotearoa
}

\section{THREE}




\title{
Indigenous Insider Knowledge and Prison Identity
}

\author{
Tracey Mclntosh and Stan Coster
}

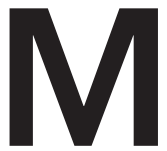

UCH SOCIOLOGICAL AND criminological research pertaining to Māori and other Indigenous peoples is complicit in the silencing of Indigenous experiences and perspectives in the pursuit of crime control knowledge' and this research and its applications are experienced by Indigenous peoples as 'a component of epistemic violence of settler colonial crime control'. 'The Māori experience of colonisation is paralleled by the struggles of Indigenous peoples in other settler states, who have also been systematically brutalised and marginalised by state policies and practices-contributing to the disproportionality found in prison populations. ${ }^{2}$ Indigenous sociology and crimi-

1 Chris Cunneen \& Juan Tuari, Indigenous Criminology, Bristol 2016, p. 28.

2 Robert Webb, 'Incarceration', in Tracey McIntosh \& Malcolm Mulholland, eds., Māori and Social Issues, Wellington 2011. 
nology offers both a critical frame and a form of resistance to the dominant social construction of Indigenous peoples, both at the individual and collective level. It privileges the perspectives, experiences, and issues of Indigenous peoples while critically analysing the activities of powerful state actors. ${ }^{3}$ This article draws on the personal experiences and state documentation of Stan Coster (Ngāti Kahungungu) whose life has been characterised by different forms of state confinement, including over 25 years in prison serving both short and long lags. Through the use of the Official Information Act, Stan recovered state documentation on himself spanning over 40 years. Stan is not a research participant, but a full research collaborator and is engaged in all elements of this paper, so while not a writer he is both auteur and author of this piece. His ongoing engagement with (state-funded) university-based researchers is part of his talking back to the state. ${ }^{4}$ Stan's story is his own and yet many of its features speak to a much broader collective experience. His prison identity and gang identity can be seen as being both informed and generated by state sponsored activity. By traversing the issues that pertain to the crisis of mass imprisonment, Māori disproportionality in the prison system, the contribution of the state to prison, and gang identity, we look at the possibilities of drawing on knowledge acquired under conditions of state constraint.

Stan Coster's life narrative demonstrates the centrality of state institutions in his life. Well before his birth his family had come to the attention of Child Welfare and other agencies. Since becoming a ward of the state at nine, the state took on the role of parent as well as taking on the role of prison warden in

3 Biko Agozino, 'Imperialism, crime and criminology: Towards the decolonisation of criminology', Crime, Law and Social Change, 41/4 2004, pp. 343-58.

4 Dominic Andrae, Tracey McIntosh \& Stan Coster, 'Marginalised: An insider's view of the state, state policies in New Zealand and gang formation', Critical Criminology, DOI 10.1007/s10612-016-9325-8, 2016. 
subsequent years. Though he has been out of the prison for over 15 years the state still continues to play a significant role. Agents of the state remain a feature of his life, and as Stan remarks 'The State has written my life and made me the person I am'. ${ }^{5}$ His story is not a redemptive one that speaks to a 'life turned around', rather it is a story of resistance to the ongoing barriers he faces. It is a bare life but it is also a considered life. ${ }^{6}$ Years of institutionalisation have given him insight to the system that has shaped and continues to inform his life. He recognises that things could have been different for him if opportunity rather than deprivation had characterised his early years. ${ }^{7}$ Stan's confinement in children and youth facilities and later adult incarceration consistently marked a narrowing of prospects, and the further embedding of a marginalised status. While crisis has been a feature of his personal life the ongoing crisis of mass incarceration of Māori is a part of our collective life.

\section{Concealed crisis}

It has probably been said in all ages and at all times that we are in a time of crisis. Just as conflict is the motor of history, crises are often the defining events that delineate and illuminate the nature and substance of the current social environment. Crises are, then, the stuff of life. They generate fear and pervasive anxieties and engender a range of responses. It would be difficult to dispute the fact that we are currently immersed in multiple cri-

5 Stan Coster, 'The state as parent and warden: Stan's story', in Max Rashbrooke, ed., Inequality: A New Zealand Crisis, Wellington 2013, p. 132.

6 Georgio Agamben, Homo Sacer: Sovereign Power and Bare Life, trans. Daniel Heller-Roasen, Stanford 1998.

7 Coster, 'The state as parent and warden'. 
ses that are global in spread and in impact. Giorgio Agamben has alerted us to the notion that post 9/11 many states see themselves in a perpetual state of exception, and that they draw on this to legitimise unusual extensions of power as strategies to exercise power, articulate often extra-judicial responses, and to defend the interests of elite groups. ${ }^{8}$ He also clearly demonstrates that it is times of crisis that create the conditions for state power to wilfully withdraw the guarantees of legal protection and entitlement. He notes that this characteristic of late capitalism has come to constitute the basis of modern state power.

There is recognition that we are currently experiencing an ongoing global financial crisis that has brought deprivation to many and fortune to few. There are also crises that resonate across the body politic that are heralded by public proclamation and global responses. These are the crises that are treated with urgency, where the language and representation employed leave no misunderstanding of the gravity of the situation and constantly reinforce the need for grave measures to be taken. These are the visible crises of our time.

Other crises are sustained and embedded. These are crises whose rupture runs deep but remain largely indiscernible to the majority. As noted elsewhere, the warehousing of surplus humanity in prisons and the ongoing carceralisation of Indigenous communities is largely a silent crisis, one that has resulted in a profound unfreedom for Indigenous peoples and other targeted groups within the settler states. ${ }^{9}$ As Angela Davis notes,

[The] prison functions ideologically as an abstract site into which un-

8 Georgio Agamben, State of Exception, trans. Kevin Attell, Chicago 2003.

9 Tracey McIntosh \& Leon Radojkovich, 'Exploring the nature of the intergenerational transfer of inequalities experienced by young Māori in the criminal justice system', in Deidre Brown, ed., Indigenizing Knowledge for Current and Future Generations, Auckland 2012. 
desirables are deposited, relieving us of the responsibility of thinking about the real issues afflicting those communities from which prisoners are drawn in such disproportionate numbers. This is the ideological work that the prison performs - it relieves us of the responsibility of seriously engaging with the problems of our society, especially those produced by racism and, increasingly, global capitalism. ${ }^{10}$

Competing narrative flows exist that, on one hand, profess knowledge of the over-representation of Māori in prison and, on the other hand, continue to disavow the damage that high incarceration inflicts on our whānau and communities. This ability to simultaneously reveal and conceal the nature of the experience of prison in Māori life-worlds shows the power of a discourse that renders the prison a natural part of the social environment for specific groups. While they remain unproblematised and largely invisible both as institution and as experience, they are not invisible as the most overt manifestation of state power and as architectures of control. In Aotearoa/New Zealand, they are largely holders of Māori. More specifically, they are holders of particular veins of Māori society. ${ }^{11}$ If it was simply a Māori issue then we would expect to see Māori prisoners coming from all socio-economic categories and reflecting the broader Māori population. Yet the Māori prison population overwhelmingly comes from communities that live under conditions of scarcity and deprivation.

It is also important to recognise that the Māori experience of prison is gendered. To fully understand the inter-generational aspects of prison life in New Zealand it is thereby critical to likewise understand the experiences of Māori women. While

10 Angela Davis, Are Prisons Obsolete? New York 2003, p. 16.

11 Tracey McIntosh \& Kim Workman, 'Māori and Prison', in Antje Deckert and Rick Sarre, eds., Australian and New Zealand Handbook of Criminology, Crime and Justice, Melbourne 2017. 
work has been done in this area there is much more to be done. ${ }^{12}$ While recognising the need for more balance in the discussion on prison identity, this article will largely focus on the male prison identity.

\section{Thinking over-representation}

The normalisation of 'over-representation' means that the term is often perceived to be a natural attribute of a particular group. As Indigenous scholars and social justice practitioners who constantly face the challenge of engaging with the issues of over-representation, we should be exploring better terminology that more effectively captures the experience of disproportionate incarceration rates. Simone Bull has already argued that over-representation is the wrong paradigm. ${ }^{13}$ She notes that any analysis on Māori and the criminal justice system starts with the acknowledgment

12 Venezia Kingi, The Children of Women in Prison, unpublished PhD thesis, Wellington 1999; Glennis Dennehy \& Greg Newbold, The Girls in the Gang, Wellington 2001; Sophie Goldingay, 'Jail mums: the status of adult female prisoners amongst young female prisoners in Christchurch Women's Prison', Social Policy Journal of New Zealand, 31 2007; Khylee Quince, 'Māori and the criminal justice system in New Zealand', in Warren Brookbanks \& Julie Tolmie, eds., Criminal Justice in New Zealand, Wellington 2008; Tracey McIntosh, 'Marginalisation: A Case Study: Confinement', in Tracey McIntosh and Malcolm Mulholland, Mãori and Social Issues, Wellington 2011; Hannah Bentley, The Cycle of Female Prisoner (Re)Integration: Pathways, Criminal Justice and Imprisonment, unpublished MA thesis, Wellington 2014; Lily George et al. 'Historical trauma and contemporary rebuilding for Māori women with experiences of incarceration', MAI Journal 3/3 2014; Rebecca Wirihana \& Cherryl Smith, 'Historical trauma, healing and wellbeing in Māori communities', MAI Journal 3/3 2014; Marianne Bevan \& Nan Wehipeihana, Women's Experiences of Offending and Rehabilitation, Wellington 2015; McIntosh and Workman, 'Māori and prison'; Tracey McIntosh \& Bartek Goldmann, 'Locked up: Incarceration in Aotearoa New Zealand', in Avril Bell, Vivienne Elizabeth, Tracey McIntosh \& Matthew Wynyard, eds., Land of Milk and Honey? Making Sense of Aotearoa New Zealand, Auckland 2017.

13 Simone Bull, 'Changing the broken record: new theory and data on Maori offending', unpublished paper delivered to the Institute of Policy Studies, Wellington 2009. 
of Māori over-representation in the system and the discussion then swiftly proceeds without interrogating the notion of overrepresentation. She posits that the focus on over-representation ignores the roles of criminogenic factors. Rather than comparing the proportion of Māori apprehension to the proportion of Māori in the general population, attention should be concentrated on

whether the proportion of Māori who are young, male, unmarried, unemployed, uneducated, in substandard housing, is reflected in the apprehension statistics. Rates of recorded offending, and hence imprisonment, are well known to depend on a range of social development factors ... rather than raw population proportions. But, we have never undertaken research to test whether Māori are still over-represented in the criminal justice system once you control for known criminogenic variables. ${ }^{14}$

Over-representation, while descriptively correct, is not a useful designation because it is monolithic in concept and practice. It tends to depict the prefix as unproblematic (hence naturalising it) and most importantly renders invisible the social structures and mechanisms that engender it. Over-representation becomes another tool of confinement that speaks to and confirms the existing situation of not only those who are currently incarcerated but also to the enduring cycle of incarceration. In some ways it describes the systemic churn that ensures that, for too many, the prison may be perceived as one's destiny. Is prison a matter of descent-some form of genealogical inheritance-or is it related to dissent-an act of resistance against mainstream societal norms that have largely ensured the 'systemic frustration 
of aspirations' for Māori? ${ }^{15}$ While we struggle to come up with a word that replaces over-representation we remain aware of how closely the word, its use, and the experiences associated with it speak to high levels of institutional racism, social constraint and blocked opportunities.

\section{Constraint and insider knowledge}

All of us live lives that are bound, constrained, and contained. Yet the limits of those boundaries and the tightness of the tethers are socially differentiated and regulated. The contemporary experience of Māori incarceration is one where the centrality of the prison as a dominant institution casts a long shadow over collective life. It shapes and informs identity at the personal and shared level. Teachings about the incarcerated experience are not just learnt behind the wire, but are also disseminated in related youth institutions and in communities characterised by scarcity and deprivation. Moreover, this insider knowledge reaches across communities and across generations. The Māori prison identity is one that is formed both within and outside the prison walls.

Knowledge generation occurs in many settings. For many Māori, knowledge learnt within institutional settings has had inter-generational reach. What do institutions teach us? A first lag in prison may be compared with the contraction of a

15 Ivo Feieraband \& Rosalind Feieraband, 'Aggressive behaviors within polities, 1948-1962: a cross-national study', Journal of Conflict Resolution, 10 1966; Johann Galtung, 'Feudal systems, structural violence and the structural theory of revolution', Revista Latinoamericana de Ciencia Politica, 1/1 1970; R. Khan, 'Violence and socio-economic development', International Social Science Journal 30/4 1978; Anne K. Eckermann, 'Aboriginal education in rural Australia: A case study in frustration and hope', Australia Journal of Education, 43/5 1999. 
serious illness. If diagnosed with cancer within a very short time the disease would have introduced the sufferer to a knowledge system that includes: treatment paths; medication protocols; specialists; new regulatory environments and their associated administrators and enforcers; compliance codes and a specialised lexicon that allows access to new ways of knowing and being with its own linguistic subtleties. In other words cancer, in a short timeframe, instructs the sufferer with a novel range of specialised knowledge that is largely outside of the purview of the nonsufferer. This is at once intimate knowledge and shared knowledge within the confines of medical and related institutions.

The learnt knowledge and the experiential element is identity changing. Once this knowledge is learnt it cannot be unlearnt, even if the sufferer returns to robust good health. So it is with prison. The intensity of the experience, coupled with the distinctiveness of the regulatory environment and its encompassing tendencies, mean that the prisoner learns not just about the everyday working of the prison, but also its language, its complex apparatus, its diverse codes, and the way that power is exercised in different social settings. ${ }^{16}$ The prison becomes, for example, a proficient teacher of the need for hyper-vigilance of your surroundings and the people that inhabit it. This hypervigilance counter-intuitively may be coupled with a detachment from those same surroundings. This means that the incarcerated individual may be alive to the workings of the institution and at the same time apathetic or removed from active participation. Hierarchies are identified and responded to, and quickly one has expert knowledge that sets one apart from those that do not share this knowledge. This setting apart is reinforced by the associated stigmatisation of the prison identity that in turn further

16 Erving Goffman, Asylums: Essays on the Social Situation of Mental Patients and Other Inmates, Harmondsworth 1968. 
strengthens its individual and collective elements. Institutionalisation speaks not only to the deleterious effects of confinement but to an embedded quality that remains even once the institution is no longer present.

The swiftness of the uptake of both the knowledge and the prison identity is determined by the level of preparedness for the prison encounter. The research of Liz Gordon and Lesley MacGibbon, in their study on children of prisoners (in which they interviewed 217 prisoners: 129 men and 88 women), speaks to this issue. Of the men interviewed $48 \%$ were on their fourth or subsequent prison sentence, which the researchers see as supporting the contention 'that prison strips communities of their young men often for extended periods' ${ }^{17}$ They also noted:

That there were strong signs of intergenerational recidivism among the Māori sample. Two-thirds of that sample had seen someone they lived with as a child go to prison, compared to one-third of the nonMāori. The most likely relatives to have been imprisoned were, in order, father, uncle, brother, cousin and mother. Around half of the sample had visited prison as children, most on multiple occasions. ${ }^{18}$

However, they believe that their findings did not support the notion that prison had been normalised prior to incarceration for these participants. They noted that less than a quarter indicated that they knew a lot about prison life prior to being incarcerated. We argue that the normalisation may have less to do with prior knowledge of the day to day experience of the prison or other forms of state confinement, but rather that normalisation speaks to an acceptance that prison may well be part of one's future. Prison appears not as a pre-determined destiny, but certainly as

17 Liz Gordon \& Leslie MacGibbon, A Study of the Children of Prisoners, Auckland 2011, p. 3.

18 Ibid., p. 3. 
a possibility far in excess of the expectations of the general population. Similarly, Loïc Wacquant in his discussion of the prison as both a central and a banal institution notes that in urban black spaces in the United States the prison is 'like a big rock in their personal backyards which cannot be removed or circumvented, and one that changes everything in their social landscape'. ${ }^{19}$

Linking this dynamic to the history of colonisation, Luana Ross, writing on the experience of Native Americans, argues that colonial occupation 'as control and denial of culture is clearly evidenced by the number of incarcerated Native Americans and by their experiences of prison'. ${ }^{20}$ The fact that Indigenous peoples are disproportionately held in prisons in settler states reinforces her argument. Research clearly suggests that prison is in many cases a traumatic, injurious, and fundamentally non-therapeutic environment, and that prison experiences may cause prisoners to undergo deterioration and exacerbation of physical and mental health issues. Prisons are institutions that in their architecture, systems, and policies articulate the power of the state over the individual. Those that spend time in them may also have further developed patterns of behaviour and a way of viewing and being in the world which, while perhaps useful within prison walls, are perhaps potentially maladaptive and harmful outside of this specialised environment. ${ }^{21}$

19 Loïc Wacquant, Prisons of Poverty, Minneapolis 2009, p. 111.

20 Luana Ross, Inventing the Savage: The Social Construction of Native American Criminality, Austin 1998, p. 4.

21 McIntosh, 'Marginalisation'; McIntosh and Workman, 'Māori and prison'. 


\section{Stan's story: The hard start}

Stan's experience of removal, dismissal, disconnection and deprivation is at once both an individual and collective experience. As David Cohen notes, the confinement of children is largely an invisible part of the story of Aotearoa/New Zealand. While it has been employed since the early days of contact and settlement, from the 1950s through to around 1990 child and youth confinement in a variety of residential institutions was significantly extended in response to government policy. ${ }^{22}$ In this period the New Zealand Government incarcerated not just the worst criminal offenders, who never numbered all that many, but also more than 100,000 children and young people, mostly Māori, who were believed to be in need of getting locked away'. ${ }^{23}$ Elizabeth Stanley's work centres on the accounts of New Zealanders who as children 'experienced the brutal failings of mass institutionalisation'. ${ }^{24}$ Her discussion on institutional cultures speaks to the power of state violence to imprint a sense of shame and stigma on children who, like Stan, were incarcerated in state institutions. She notes that for Māori and Pasifika children racism further intensified the processes of denigration to which children were subject. ${ }^{25}$ Many of those children that were held in these youth residences and training facilities during this period continue to churn through the prisons today. Moreover, the children of these children are also to be found disproportionately in the contemporary prison system.

Stan was one of these earlier children. In 1969, after

22 David Cohen, Little Criminals: The Story of a New Zealand Boys' Home, Auckland 2011. Henceforward LC

23 Ibid., p. 22.

24 Elizabeth Stanley, The Road to Hell: State Violence Against Children in Post-War New Zealand, Auckland 2016, p. 3.

25 Ibid., p. 59. 
the death of his mother, Stan, alongside his siblings, was placed by Child Welfare on preventive supervision with a local family. Shortly after the children were removed on warrant as being indigent and made wards of the state. For Stan the loss of his mother translated into the loss of his world, but it was not the first hardship that he had experienced. His early life was marred by intense deprivation. Prior to her death, Stan's mother had suffered a long illness that meant that she struggled with the day-to-day responsibilities of bringing up a young family under conditions of considerable scarcity. He remembers her as a loving mother who had little support and who had entered into relationships with men that were often damaging to her and her children. She was regularly hospitalised due to her illness and the children had periods of having little or no adult supervision. During this period, social welfare reports document concerns raised that the children were being inadequately parented. The school they were attending noted that while the children were well behaved they often arrived at school unkempt and seemingly under-nourished. ${ }^{26}$ In the years immediately prior to her death, Stan's mother entered into a relationship with another man and violence became a regular feature of Stan's life, both as a victim and as an observer. The violence that was learned here would be further developed under conditions of state care.

\section{Homes of confinement}

The trauma of the death of his mother was exacerbated by the nearly continual movement from foster home to foster home. While in the period immediately after his mother's death at- 
tempts were made to keep the children together, or at least in pairs, this proved too difficult to sustain and was quickly abandoned by the authorities. Official welfare reports of the time testify to his frequent movements of homes and schools. In less than one year he had been moved five times, between three different regions. There was a pattern in his placements: early reports often indicated that after initial difficulties he was settling well and that the foster parents were confident that he would adapt to his new circumstances. Yet often only weeks later the Department of Social Welfare officers would be reporting that Stan was uncommunicative and disruptive to the routine of the foster family. For Stan, these families were strange and he was often suspicious of their intentions and too often these suspicions turned out to be warranted. He was mostly placed in Pākehā families and in one case, while the foster family no longer wanted to keep him, they were reluctant for him to be placed with a Māori family as they felt that this would reflect poorly on them. They thought it would indicate that they could not manage a Māori child. The social worker was sympathetic to their concerns and said that if he was placed with a Māori family it would be in another region.

He was placed both in private foster care as well as in children's homes. His memories of this time are bleak and he saw and suffered abuse and felt that he was in a constant state of rejection. Psychological reports from this time saw him as a traumatised child who was vulnerable to bullying, shy yet impulsive, but showing real promise as a rugby player. These reports also noted the first clear indications that he could resort to violence if frustrated or angry. Given that he had been subjected to past violence and that he remained a target of violence from both adults and his peers, his violence could be understood as a form of resistance to ongoing victimisation. This approach to resistance was a central characteristic that was to shape his later life outcomes. For Stan violence became a rational response to his 
environment. He says that as he got older, he realized spontaneous acts of violence or disproportionate reactions to incidents built a reputation for himself that meant he was less likely to be bullied or targeted. ${ }^{27}$

Until he was 15 this movement within the foster and collective care system continued. Increasingly, however, Stan was getting into trouble. He was picked up for successive minor infractions: petty theft, truancy, running away, and drinking, all of which were noted in Department of Social Welfare reports. Days after turning 15, after a series of minor incidents and having been a ward of the state for six years, Stan was sent to Epuni Boy's Home. His admittance to Epuni reinforced an emerging criminalised identity. At Epuni Stan's education of things criminal expanded significantly, and fighting became a much greater part of the way he engaged with the world. ${ }^{28}$

\section{The Epuni Boy's Home legacy}

David Cohen's history of Epuni is important. He was himself at 13 a resident of Epuni and he weaves insider experience, archival research, policy, narrative, and participant accounts to interrogate the design, implementation and outcomes of the residential training school experience. The year that Stan entered Epuni Boy's Home (in the mid-1970s) was the year that David Cohen used to exemplify the role that Epuni played in the government's policy on containing 'problem' children. Cohen notes that the residence was charged in 1975 with 'assessing and classifying the estimated 350 children aged between seven and 16 who at [that] 
historical point [were] pushed through its doors before passing out again, usually to some other form of state-sponsored residence or foster situation'. ${ }^{29}$

Epuni Boy's Home in Lower Hutt was just one of 21 similar institutions throughout New Zealand. While the average age of children sent there was 13 , there were both younger and older children, which in itself caused problems. The different ages of children and the varoius reasons they were sent (some for care and protection, others for criminal or status offending) created the conditions for endemic violence. This was certainly not an exclusive characteristic of Epuni Boy's Home. A report commissioned by the Ministry of Social Development on another of these institutions, the Kohitere Boy's Training Centre, looked at the experiences of residents and staff over the period from 1950 to 1985 in response to historical claims about mistreatment at the centre. ${ }^{30}$ Kohitere was established as a rehabilitation centre for young male offenders (mainly in the 14-17 year old age group). Its programmes largely included vocational training but also offered limited educational programmes. Residents came from all over Aotearoa/New Zealand and the centre was seen as the last place for young offenders before being sent on to borstal. While in the 1950s there was a short time when there were more Pākehā residents than Māori, for the most part young Māori were the majority residential group. The report noted a few key characteristics that impacted on their life at Kohitere and it could reasonably be argued would likely have an enduring impact long after their release.

Many of the residents had already been in other Boy's Homes and had already learnt and complied with a strict code of silence. They were unlikely to inform on other residents or staff

$29 \quad L C$, p. 39.

30 Ministry of Social Development, Summary of Understanding Kohitere, Wellington 2010. Henceforward SUK. 
due to fear of reprisal and the stigma of breaking the code. The power relations amongst residents were highly hierarchical and bullying was pervasive. The report noted that while a culture of bullying fluctuated over time it seems that it was most prevalent during and after the late 1970s. The difference in age of residents meant that there was considerable disparity in terms of experience and size. In simple terms this meant that smaller residents were more vulnerable to larger residents and practices to protect smaller and younger residents were largely unsuccessful. Experience was another significant factor. Over time the seriousness of crimes committed by some residents increased, while other residents continued to be sent to Kohitere for relatively minor offences such as theft. This meant that those with minor infractions were being placed into an environment with more sophisticated and often more violent residents. Some violent young people were specifically sent to Kohitere when they were not able to be held elsewhere. ${ }^{31}$ As David Cohen notes in reference to Epuni Boy's Home:

The changing reality created something of a vicious circle: if the residence had become, almost without realising it, an operating arm of the youth justice system, the residential realities at Epuni meant that the institution was creating further work for the courts. The economics of the place meant that housing different individuals according to their experiences and problems was out of the question. So somebody with a relatively stable disposition, including those sent down by the courts for fairly light offending, would therefore find himself in the daily company of others with serious criminal records .... The arrangement also had the potential to cause serious problems among the boys who were simply in Epuni because they required temporary shelter. If a kid of 10 whose worst offence was having a violent mother ended up living cheek by jowl

31 Ibid., pp. 6-7. 
with a 17 year old murderer .... It was not difficult to figure out who was going to come out the worse for the experience. ${ }^{32}$

The training that many received was not the type of training originally envisaged for the residents of the youth institutions.

By the 1970s the majority of residents at Kohitere and Epuni were similar to the demographic make-up of the other 21 children and youth residential homes, in that they were predominantly Māori. They came from all over the country, such that contact with their families and communities was disrupted; in some cases this disruption was to be permanent. ${ }^{33}$ While in 1959 around one in every four boys admitted to Owairaka Boys' Home in Auckland was Māori 'over the following decade the figure rose to seven in every 10 admissions, and by 1978 it had reached 80 per cent'. ${ }^{34}$ Tariana Turia, the past co-leader of the Māori Party, commented years ago that the residential schools turned children into 'slaves for the colonials'.

Like Stan, some came from backgrounds where they had been maltreated by family members, caregivers, or staff at other boy's homes and so harboured a deep mistrust of adults. Others were wary and fearful, and found the conditions present in residential homes anxiety producing. Others, again like Stan, had become accustomed to being locked up on their own at previous institutions and had come to prefer this to being exposed to other residents. Thus, they were not always well motivated to keep out of the secure unit at Kohitere (or other secure units at the other residences) and even purposely contravened regulations so that they would be placed in the unit. Other residents had being

$32 \quad L C$, pp. 150-1.

33 SUK, p. 7.

34 LC, p. 129.

35 Quoted in $L C$, p. 202. 
living on the streets prior to being sent to Kohitere and faced significant adaptive challenges before they could be integrated into the institution. Some faced solvent and other substance misuse, while others suffered from mental health issues. By the late 1970s some residents had gang affiliations and this became a source of control, bullying, and prospecting. ${ }^{36}$ Clearly not only were the homes not therapeutic for many residents, but they also set up pathways for further institutionalisation and the formation of an inmate identity that would resonate within and outside of the wire.

\section{After Epuni}

Stan's release from Epuni was not a liberation. Though he had been a ward of the state for nearly half of his life, state parenting had not been able to provide him with stability, security or safety. He had had training, but it was largely in the norms and values of a group of young people which had been marginalised and stigmatised. The institution had taught Stan much that would carry him through the next 25 years; it would allow him to survive incarceration but provided few other benefits. Shortly after his release he appeared before the court on a number of occasions for car conversion and related charges. In 1976, after been convicted on some of these charges, he was sent to Waikeria Borstal and simultaneously discharged from Social Welfare care. The role of the state as parent had concluded and was replaced by the role of prison warden. By this time Stan was a quiet, sometimes violent, often unstable young man. The state had provided ample opportunity for his prison identity to be de- 
veloped and nurtured and had also been critical in supporting gang formation and sustaining gang identity.

While Stan is no longer a patched member of the Mongrel Mob, his earlier gang affiliations remain an important element of his identity: 'the Mongrel Mob was always a part of my life, family members were in the Mob so it has never been a gang in my eyes; it is just whānau'. ${ }^{37}$ His body and face are inscribed with his gang association and so, even as an ex-member, his tattoos present to mainstream society a gang profile. In reflecting on his life Stan feels that much of his path was determined from the start, with things consistently worsening as the years went by. In many ways his gang membership, though not always an easy association, is the most enduring and sustained relationship he has ever had.

Even years after giving up his patch his sense of the gang as whānau remains. His gang association also speaks to his ongoing resistance to the state and its policies. His understanding of gang formation as a response to the alienation of Māori from our land and our culture is apparent as he states:

I don't know the Māori ways. There were two world wars. They took the old people ... no-one left to teach us. Our own people fucked us over 'cos they sold out and gave away to the Pākehā. Our land went, so did our heritage. We are now second class citizens in our own country. How do you learn about being Māori? ... The only system I know, the old way, the hori (poor Māori) way, was to do whatever we wanted when we wanted. There has been a migration from Māori to colonialism. New cultures have been created. Mongrel Mob and Mongrelism is one of these. I never recognised the Pākehā system ... never been part of it. Why listen to the white man? All he does is steal and lie. By accepting the white man's regime, we have 
accepted the bringing of colonialism into our world. Mongrel Mob rejects the British and their colonialism. ${ }^{38}$

Others who spent time in the residential homes in the 1960s and 1970s speak to how it impacted on their later lives and in many cases encouraged gang formation. Gary Gerbes, a Pākehā founding member of the Mongrel Mob demonstrates the link:

A lot of these guys (early Mongrels) went through the same place -Levin Training Centre and Epuni Boys' Home .... It was pretty sad and pretty demoralising - there was sexual abuse by the people that ran the place [and] absolutely shocking violence. I was just a kid and I ran away once. I was made to stand on a square at strict attention and talk to myself. If I stopped saying "legs, legs why did you run away" I would be beaten and thrown in a shed-locked in a shed .... Those places destroyed our fuckin' heads, man. [So we said] fuck the system. If that is the way they are going to treat us, then we will treat them the same way. We are going to give them what they gave us—and [via the Mongrel Mob] they got it alright. ${ }^{39}$

While gang members do not comprise the majority of the prison population, Māori members make up a disproportionate number of the prison muster. The following numbers do not capture all those that are associated with gang members but it goes someway in indicating how the prison profile is shaped by gang membership. In 2008, 18\% of all inmates were gang members and two-thirds of all of these belonged to either Mongrel Mob or Black Power. ${ }^{40}$ Backgrounds of gang members, in terms of en-

38 Andrae, McIntosh \& Coster, 'Marginalised: An insider's view of the state'.

39 Quoted in Jarrod Gilbert, Patched: The History of Gangs in New Zealand, Auckland 2013, p. 42

40 Rawiri Taonui \& Greg Newbold, 'Māori Gangs', in Tracey McIntosh \& Malcolm Mulholland, eds., Māori and Social Issues, Wellington 2011, p. 222. 
gagement with state agencies prior to incarceration, are typically very similar.

Tyrone Marks, a child from a large family, was removed from his home by Social Welfare when his family was experiencing significant financial difficulties. Like Stan, he was placed in many institutions all over the country. By 12 he was at Epuni Boy's home and from there he went on to the horrors of Lake Alice Hospital, a rural psychiatric hospital with a children's unit, where he was 'treated' with Electroconvulsive Therapy (ECT). ${ }^{41}$ He declares:

It's the same thing they did to the Aborigine children, you knowtaking them off to state institutions because, they said, these kids were from large families and couldn't be dealt with any other way. So we ended up in places like Epuni, and all those other homes, festering over a number of years, feeling like shit, and you know, ending up in a life of crime after years of being repeatedly told that we were useless, you know, and no good for anything else. That's what happens if you tell someone that for long enough. It happened to me too. Same thing later on when it comes to jobs. You've got the background and then, because of it, you don't have a degree or a diploma or anything, so you're basically useless. You're a non-contributor. You're fucked. ${ }^{42}$

41 The New Zealand Government finally recognising the terrible abuse that occurred at Lake Alice Hospital under the auspices of chief child psychiatrist Dr Selwyn Leeks. Former Lake Alice patients, with an average age of 11 were given ECT as a punishment for misbehaviour in line with Dr Leeks conviction that ECT could be used as an aversion therapy as 'a way of putting wayward young patients back on the straight and narrow' (Cohen, LC, p. 142). Retired High Court judge Sir Rodney Gallen, who was appointed by the Government to divide up compensation among claimants, reported that as well as 'therapy as punishment, the children were locked away with insane adults and subjected to sexual abuse'. He further said: 'I am satisfied that in the main the allegations which have been made are true and reveal an appalling situation. Statement after statement, in many cases confirmed on interview, refer to systems, patterns of behaviour, punishments inflicted and a way of life imposed which I have no doubt was established and enforced by those in authority' (Martin Johnston, 'Former Lake Alice patients win $\$ 4.2 \mathrm{~m}$ payout', New Zealand Herald, 31 July 2004)

Quoted in $L C$, p. 131. 
While Marks later went to university and become a trained counsellor he is aware more than most of the damage that was done to children, particularly Māori children, in the residential system. In talking about the impact of children being subjected to ECT Marks articulates a deeply disturbing insight:

But who I feel the most sorry for, and I have a lot of empathy for, [are] the kids who were only kids with me who never made it. That's a lot of people we're talking about, too-thousands have been institutionalised. And you know, they went on to have their own children and stuff but never see them, so their own kids are, you know, they're the ones out murdering ... and stuff like that. And people ask why. People don't know what happened to create all this anger. $^{43}$

For Stan the 20 years that followed his time at Waikeria Borstal was largely spent in prison. The years prior to entering the adult prison system socialised and normalised him to the prison condition. Confinement was what he knew and what he adapted to and even became comfortable with. Stan is from a group of men who has been largely brought up in male environments with particularly ways of expressing their masculinity. While he spent short periods on the outside he continuously returned to prison, sometimes for relatively minor offences and breaches and sometimes for serious offences. While Stan recognises that he was thoroughly institutionalised and had an intimate understanding of the workings of the prison system, he remained a challenging prisoner within the structure. His marginality is further inscribed by both gang and jailhouse tattoos covering his face and entire body. These tattoos, only done under conditions of confinement, are an integral part of his identity and his self-proclaimed marginality. 
Stan recognises that he is an expert of the prison system. He understands its underpinnings as one of suppression and oppression. He sees this as the way of the world which is only made explicitly manifest within the prison system. Like those who have never been to prison, he also cannot imagine a world without prison. It was not until his last long term of prison that he resolved to respond differently to the system and became determined to remain on the outside on release. He engaged in prison programmes where he had earlier rejected any attempts by prison staff to enrol him in such courses. While he found them to be 'largely useless' it did allow him to think differently about the nature of 'the game of prison life'. He also started to focus on self-directed ways of healing and to reflect on the trauma he had suffered, both in personal ways and structural ways. As noted earlier, he does not see his narrative as a redemptive one that admits solely to personal defects that are remediated, and that would then allow him to suddenly integrate into mainstream life. There is no integration and there is little rehabilitation. His life remains hard and, as he notes, he has had to 'use his prison mind to navigate the outside world'. The idea that he now lives in a state of freedom is one that he clearly rejects. There is little space in the outside world that he can freely negotiate. For him the carceral ideal is constantly replicated in a world that seeks to contain him and to pull the chain. The possibility of prison remains a constant and he is often conflicted on what he sees as the gravitational force of the prison. He also sees the prison as having a function in his life. Once, when a whānau member said that they would look after him in old age, he rejected the suggestion completely, intimating that he would rather return to prison than be cared for. As he said 'when the time comes the state can wipe my arse'.

He would like, however, to use his experience to support young people and attempt to keep them out of the system. While 
he sees racism as endemic and is not naïve in his appreciation of structural issues that create and attempt to control them as an underclass, he does believe that his knowledge has value. $\mathrm{He}$ has already seen the next generation of young Māori men and women embarking on a prison life. He recognises that an expression of tino rangatiratanga is to effect positive change for your people. To achieve even modest gains is a constant grind as he continues to be a subject of scrutiny and surveillance by agents of control. Stan has caused social harm in the past and he does not minimise this, but he also reflects on the level of social harm that he was subjected to as a young boy and youth. Stan is able to offer insight into his life: 'I have spent most of my life within four walls, having created my own reality. I am a product of the system'. ${ }^{44}$

\section{Prison and gangs inside/out}

John Braithwaite points to the fact that the very purpose and design of prisons is to exclude criminalised individuals from the wider social group, and if adequate efforts to establish reacceptance and integration are absent then the stigma of imprisonment is more firmly embedded. ${ }^{45}$ Kim Workman argues that although research exists on the differences between Māori and non-Māori offending, and of some research which examines the impact of imprisonment on the families of prisoners, 'there is almost nothing that describes the stigmatisation and labelling of

44 Coster, 'State as parent and warden', p. 133.

45 John Braithwaite, Restorative Justice and Responsive Regulation, New York 2002 . 
prisoners on release'. ${ }^{46}$ Workman argues that this is a key contributor to Māori disproportionality in the prison system. Historically, Māori ex-prisoners have been denied the opportunities for redemption and integration. Further, Workman argues that if Māori recidivism is to be addressed, research into this area must be a key priority. Julia Carr and Harry Tam, in drawing on the use of the designation of 'hard to reach' (particularly as it relates to gang members and their families), also argue that:

Through this social exclusion process, individuals and groups lose some of their rights as citizens, and become disengaged from services, opportunities and responsibilities. The term also recognises that members of these groups are citizens, community members, and have been part of families. The hard to reach definition allows interventions to tackle issues and behaviours without exacerbating the problem through further marginalisation. ${ }^{47}$

It would be difficult to argue that the integration of prisoners is done well for any group in Aotearoa/New Zealand, but it is clear that the stigmatisation and marginalisation of whole sectors of Māori communities means that the effects of prison are likely to be more keenly felt within that community. Moreover, the Māori prison identity has a collective element which means that the rejection of mainstream values can be seen as an act of dissent and resistance. While this article does not specifically look in any depth at gangs and prison, ${ }^{48}$ it is important to appreciate that gang affiliation-as a patched member, or as an associate, or as

46 Kim Workman, 'Māori over-representation in the criminal justice system does structural discrimination have anything to do with it', unpublished paper, Rethinking Crime and Punishment, Wellington 2011, p. 8.

47 Julia Carr \& Harry Tam, 'Changing the lens: Positive developments from New Zealand', International Association of Youth and Family Judges and Magistrates, 1, 2013, p. 16.

48 Andrae, McIntosh \& Coster, 'Marginalised: An insider's view of the state'. 
a family member-has contributed strongly to the contemporary Māori prison identity. Carr and Tam note that it was during the 1980s that the traditional prison culture became dominated by gang prison culture. ${ }^{49}$ While gang affiliation in the general population is small, its presence within the criminal justice system and specifically the prison system is marked. ${ }^{50}$ As already noted, the state residential homes have already played a role in gang formation.

Gang formation is nothing new in Aotearoa/New Zealand. Rawiri Taonui and Greg Newbold argue that different forms of exclusion and alienation generate different types of gangs. They posit that in Māori and Pasifika gangs alienation is characterised by intergenerational impoverishment, structural marginalisation and trauma of European colonisation and postcolonial dominance'. ${ }^{51}$ Gang affiliation in Aotearoa/New Zealand is high in smaller, relatively deprived towns and semi-rural communities, though there is also a presence in pockets of larger urban areas. The visibility of urban youth gangs has had a higher profile more recently, but these are 'generally part of a wider landscape of families and communities with intergenerational gang membership and high levels of poverty, unemployment, poor educational engagement, and poorly resourced neighbourhoods. ${ }^{52}$ Jarrod Gilbert alerts us to the way that gang membership acts, or is perceived to act, as a solution to problems confronting marginalised youth:

External forces within the wider community act to push youths towards forming or joining gangs. Those who seek gang membership,

49 Carr \& Tam, 'Changing the lens'.

50 McIntosh \& Workman, 'Māori and prison'.

51 Taonui \& Newbold, 'Māori Gangs', p. 210.

52 Carr \& Tam, 'Changing the lens', p. 14. 
however, do so because of what they believe that the gang can offer them - the pull of gang membership. The benefits, perceived or real, are such things as prestige, power, and belonging. In these ways, the gang can act as a substitute for important human social psychological factors of wellbeing that are otherwise scarce, absent, or seemingly out of reach. Rather than an anomalous manifestation in an otherwise healthy society, the gang is a symptom of certain social maladies that provides a number of important functions for its membership. ${ }^{53}$

Both inside and outside the prison, the conditions are conducive to the development of an identity that, while adaptive to conditions of constraint, is unlikely to allow individuals and communities to flourish or to live lives as Māori. Stan, and many like him, have a story to tell; one that adds insight and depth to understandings of the problems that result from racism and other forms of structural discrimination-ranging from poorly thought through state intervention to the systemic frustration of aspirations. Importantly, this story can also inform solutions. If we are to reduce our prison population we will need to embrace equality in the justice system and in the broader community. ${ }^{54}$ Māori with personal experience and knowledge of the prison system can, if appropriately resourced and supported, come up with innovative Māori-centred solutions. They are insiders (in the literal sense of the word). The privileging of this status could mean that we go beyond merely describing a condition toward new creative possibilites for positive transformative change for deprived communities. For example, work done in South Auckland by the Consultancy Advocacy and Research Trust (CART), which has experience in working with gang communities in delivering the Hard to Reach Youth

53 Gilbert, Patched, p. 49.

54 Kim Workman \& Tracey McIntosh, 'Crime, imprisonment and poverty', in Max Rashbrooke, ed., Inequality: A New Zealand crisis, Wellington 2013, p. 128. 
Project, demonstrate that it is possible to develop programmes and processes that resonate with communities. An independent evaluation of their programmes showed that people 'who have common experiences with hard to reach populations are the most appropriate people to design and deliver intervention projects because they can share their experiences of what has led them to make positive life choices' ${ }^{55}$ The fact that the trust is made up of individuals with gang affiliations and prison experience alongside key community figures, shows a respect for the knowledge and contribution ex-inmates bring. Carr and Tam note that:

The challenge is to tap into that positive potential. To do this, penetration and engagement is critical and pro-social individuals from hard to reach communities are more likely to be successful because they have particular expertise, experience and credibility. The New Zealand experience echoes finding in recent reviews to support the involvement of gangs in solutions and the limitations of using programmes of in-reach where the workers have little connection with the target community. ${ }^{56}$

These initiatives are not without significant challenges, particularly in seeking support in a politically risk-adverse environment where a hard-on-gangs approach is evident in the two main political parties. The Māori Party has supported initiatives where gang members provide both leadership and expertise but these initiatives remain fragile due to the political environment and because of the challenges the work presents. A significant barrier to transformative change remains in the (political) tendency to see change as only occurring through the changing of personal choices rather than an addressing of structural issues. Notwith- 
standing, if any gains are to be sustained it will only be when there is recognition that individuals and groups who have experienced incarceration, and are experts of their own condition, have a vital role to play in creating the conditions for change. As Māori, we would argue that culture matters and that it matters deeply. We, however, resist the notion that Māori should have to find cultural solutions to structural problems. Structural problems need structural solutions, but these can be informed by a broad range of Indigenous knowledge.

As Indigenous sociologists and allied researchers working within a settler state, we have an obligation to address the crisis of mass incarceration and have a contribution to make in ensuring that those with institutional knowledge gained under conditions of confinement are supported in telling their stories, identifying that which needs to be changed and articulating a way forward that would reduce social harm within our communities. Part of a social harm-reduction programme is ensuring that victims do not become perpetrators. A prison identity is neither an ascribed identity nor a natural identity conferred by descent. It is an identity that emerges out of structural violence and, like the structures of society, is amenable to positive change. 
If you like what you have read, please subscribe or donate.

\author{
G \\ COUNTERF UTURES \\ Left thought \& practice Aotearoa \\ (C) Copyright Counterfutures 2017
}

